\title{
INDIRECT IMPACT OF AN ACRYLIC LABIOLINGUAL SPLINTS MANGING FRACTURED PEDIATRIC MANDIBULAR DENTAL BEARING AREAS ON TEMPOROMANDIBULAR JOINT FUNCTIONS
}

\author{
Hamed Gad ${ }^{*}$ and Amro M.Moness Ali **
}

\begin{abstract}
Objective: The purpose of the current study was to investigate the indirect impact of an acrylic labio-lingual splints as a fixation maneuver of pediatric mandibular body fractures on temporomandibular joint (TMJ) function.

Study design: The current study was conducted on twenty patients of both genders (12 boys and 8 girls) with age ranging from 5-10 years old. These patients suffered from 20 single mandibular fractures at teeth bearing area. The patients were divided into two groups; pre-school age group (G1) and school age group (G2). They were conservatively treated through closed reduction and indirect fixation by using acrylic labio-lingual splint tightened by 2-4circummandibular wires under local anesthesia and conscious sedation. The patients were followed up clinically and radio-graphically immediately, and at (one, three, six, nine and twelve) months postoperatively.
\end{abstract}

Results: Through all follow up period; all mandibular functional movements well not affected. Statistically; there were non-statistically significance decrease in all functional mandibular movement in both groups. In the meantime there non-statistically significance decrease in all functional mandibular movement in the same group from immediate post-operative period to the end of the postoperative follow up period

Conclusion: An acrylic labio-lingual splints as the legendary mean of indirect fixating of pediatric mandibular body fractures had no deleterious effect on TMJ functional activities.

KEYWORDS: Circum mandibular wiring, mandibular body fractures, acrylic splint, pediatric trauma.

\section{INTRODUCTION}

Facial fractures are an uncommon occurrence in children owing to differences in the ratio between cranial and facial volume in children versus adult, moreover, the mandibular fractures in children represent approximately $40 \%$ of all pediatric maxillofacial fractures. ${ }^{1-2}$

Falling, chin trauma is reported to be a factor in the development of TMD in pediatric patients. ${ }^{3-6}$ Unilateral and bilateral intracapsular or subcondylar

* Lecturer of Oral \& Maxillofacial Surgery, Faculty of Dentistry, Minia University.

** Lecturer of Pediatric and Community Dentistry, Faculty of Dentistry, Minia University. 
fractures are the most common mandibular fractures in children. ${ }^{7}$ Closed reduction and prolonged immobilization can result in ankylosis. Improperly treated fractures may result in facial asymmetry. ${ }^{8}$

In management of these fractures, the goal is to restore the underlying bony architecture to its preinjury position in a stable fashion; with minimal aesthetic and functional impairment. ${ }^{9}$ Disruption of the periosteal envelope of the mandibular body may have an unpredictable effect on growth. Thus, if intervention is required; closed reduction is favored. ${ }^{10}$

Closed reduction techniques with maxillomandibular fixation in young children can pose several concerns, including, temporomandibular joint dysfunction, patients' cooperation, compliance and inadequate nutritional intake. Open reduction with rigid internal fixation (ORIF) of unstable mandibular fractures using mini-plates and screws are thought to have a negative effect on skeletal growth and un-erupted teeth and involve two-stage surgery because of the need for plate removal after complete healing. ${ }^{11}$ Most fractures have been treated conservatively by acrylic labio-lingual splints tightened by circum-mandibular wiring is a relatively simple technique for mandibular fractures in children. ${ }^{12}$

The purpose of the current study was to assess if there was any indirect effect of these acrylic labiolingual splints, which seem to be bulky in sizes in related to the relatively small pediatric mandibular sizes which may interfere with the normal movement ranges of the mandible during fixation period, consequently increase the possibilities of TMJ fibrous or bony ankylosis occurrences.

\section{PATIENTS AND METHODS}

The current study was conducted on twenty patients of both genders ( 12 boys and 8 girls) with age ranged from (5-10) years and suffered from mandibular fractures (symphysis, parasymphysis and body) fractures. These patients were selected from the Out Patient Clinic of Maxillofacial Department, Faculty of Dentistry, Minia University. These patients have been conservatively treated through closed reduction and indirect fixation by acrylic labio-lingual splint tightened by circum-mandibular wiring under local anesthesia and conscious sedation. The patient were divided into two groups; group one included 10 preschool age patients while group two included 10 school age patients.

The examination of the patients was carried out through both clinical and radiographic examinations. Digital standardized panoramic radiographs were taken for each case to determine the site, number, type of fractures and degree of displacement.

The fractured segments was manually reduced. Pre-injury occlusion and continuity of the inferior border were used to judge proper reduction intraoperatively. Two to four circum-mandibular wires were inserted by using the bone awl for stabilization of the splint around the fractured segments. At the beginning of the fifth week postoperatively, the splint was removed under regional blocks of local anesthesia. The patients were followed up to evaluate their general health condition, fracture healing, and mandibular activities (protrusive movement, lateral excursion movement, and maximum mouth opening). The follow up periods included: weekly in the first month and at one, three, six, nine and twelve months postoperatively.

\section{Statistical analysis}

Data were presented as means and standard deviation (SD) values. Student's t-test was used to compare between maximum mouth opening, protrusive movement, ipsilateral excursion and contra-lateral excursion of the two groups. Paired t-test was used to study the changes by time in maximum mouth opening, protrusive movement, ipsilateral excursion and, contra-lateral excursion within each group. The significance level was set at $\mathrm{P} \leq 0.05$. Statistical analysis was performed with SPSS 16.0® (Statistical Package for Scientific Studies) for Windows. 


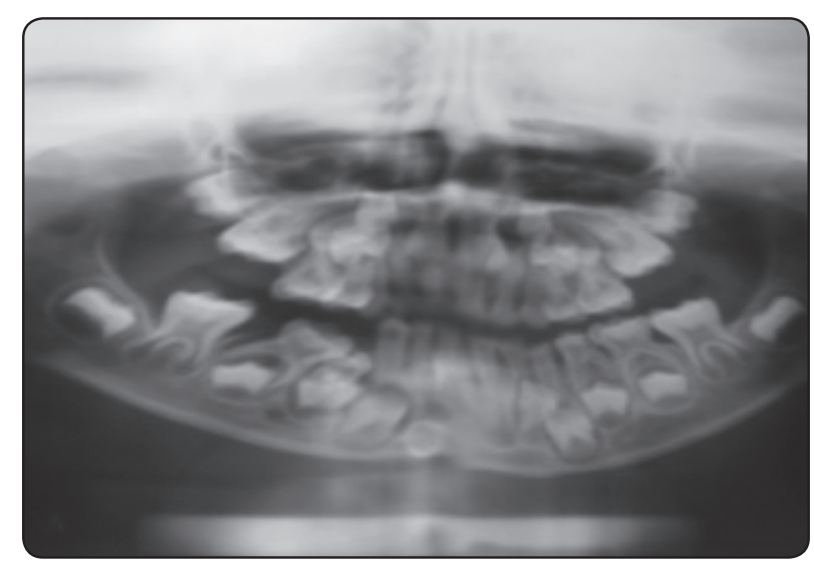

Fig. (1) Preoperative panoramic radiographic view showing right para-symphyseal fracture.



Fig. (3) Postoperative photograph showing methods of measuring maximum mouth opening.



Fig. (5) 6 months postoperative follow up panoramic view showing good alignment of the inferior border of left mandibular parasymphyseal fracture region with the right and left symmetrical dental pattern.

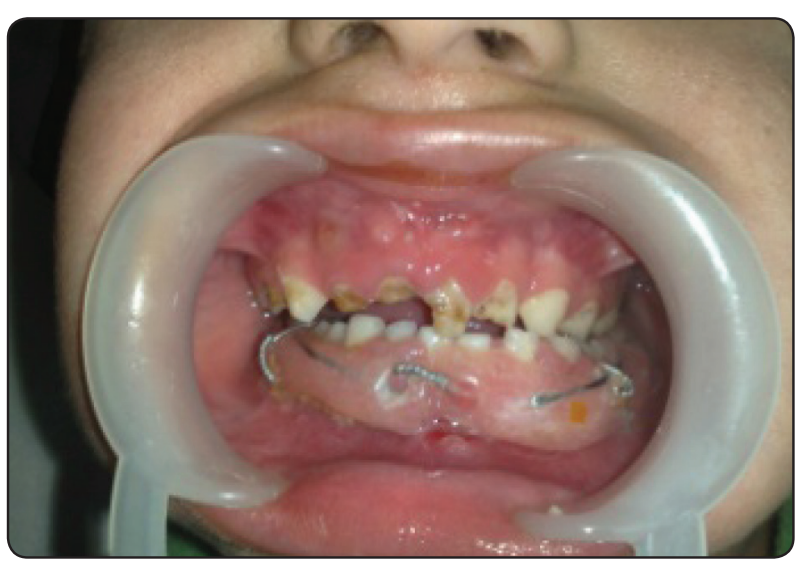

Fig. (2) Immediate post-fixation photograph, showing labiolingual splint fixed by 2 circum-mandibular wiring.

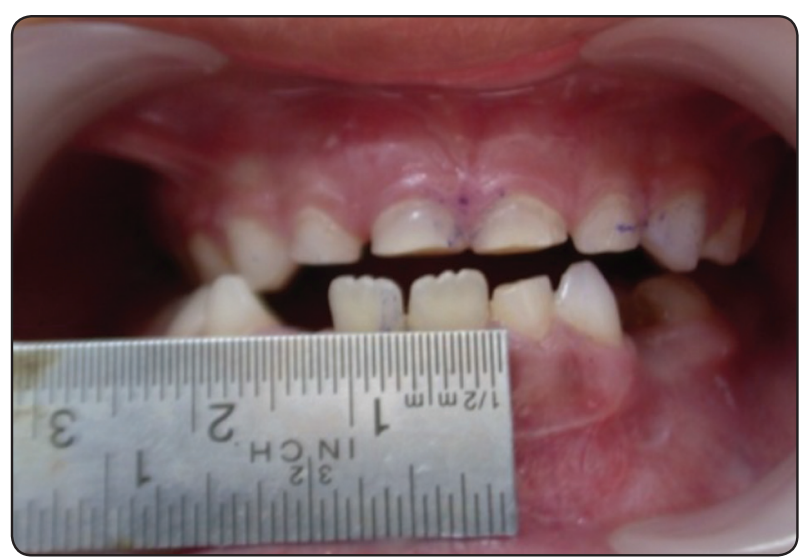

Fig. (4) Postoperative photograph showing methods of clinical evaluation of lateral excursion.

\section{RESULT}

Clinical and radiographic results obtained from this study through all postoperative follow up periods showed uneventful healing for all fractures, post-traumatic malocclusions was corrected, and shedding as well as eruption of the related teeth were normally on chronological sequences. Statistically; there non-statistically significance decreases in all functional mandibular movement in both groups through all post-operatives follow up period (tables 1-8). In the meantime there were non-statistically significance decreases in all functional mandibular movement in the same group from immediate postoperative period to the end of the postoperative follow up period 
Statistical analysis of the clinical results of different mandibular functional movement through all postoperative follow up period

\section{I) Statistical analysis of maximum mouth opening} in both groups during postoperative follow up period

TABLE (1) The mean differences, standard deviation (SD) values and results of paired t-test for the changes by time in maximum mouth opening of each group

\begin{tabular}{|c|c|c|c|c|}
\hline 苛 & Period & $\begin{array}{c}\text { Mean } \\
\text { difference }\end{array}$ & SD & P-value \\
\hline \multirow{6}{*}{$\vec{\Xi}$} & 3 months -6 months & 1.1 & 1 & $0.007 *$ \\
\hline & 6 months -9 months & 1.0 & 5.4 & 0.575 \\
\hline & 9 months -12 months & 0.8 & 0.9 & $0.022 *$ \\
\hline & 3 months -9 months & 2.1 & 5.9 & 0.286 \\
\hline & 3 months -12 months & 2.9 & 6.1 & 0.169 \\
\hline & 6 months -12 months & 1.8 & 5.7 & 0.343 \\
\hline \multirow{6}{*}{$\begin{array}{l}N \\
\cong \\
0 \\
0\end{array}$} & 3 months -6 months & -0.2 & 2.4 & 0.798 \\
\hline & 6 months -9 months & 2 & 2.5 & $0.034^{*}$ \\
\hline & 9 months -12 months & 0.7 & 1.1 & 0.066 \\
\hline & 3 months -9 months & 1.8 & 3.9 & 0.179 \\
\hline & 3 months -12 months & 2.5 & 4.1 & 0.089 \\
\hline & 6 months -12 months & 2.7 & 2.7 & $0.012 *$ \\
\hline
\end{tabular}

\section{*: Significant at $P \leq 0.05$}

In Group 1, there was -statistically significant increase in mean maximum mouth opening through the periods ( 3 months -6 months) and ( 9 months - 12 months).In Group 2, There was a statistically significant increase in mean maximum mouth opening through the periods (6 months -9 months) and (6 months -12 months).
TABLE (2) The means, standard deviation (SD) values and results of Student's t-test for the comparison between maximum mouth openings in the two groups

\begin{tabular}{|c|c|c|c|c|c|}
\hline \multirow{2}{*}{ Group } & \multicolumn{2}{|c|}{ Group 1 } & \multicolumn{2}{c|}{ Group 2 } & \multirow{2}{*}{ P-value } \\
\cline { 2 - 5 } Period & Mean & SD & Mean & SD & \\
\hline 3 months & 37.8 & 4.7 & 38.5 & 2.4 & 0.682 \\
\hline 6 months & 38.9 & 4.3 & 38.3 & 1.6 & 0.685 \\
\hline 9 months & 39.9 & 3.7 & 40.3 & 2.8 & 0.789 \\
\hline 12 months & 40.7 & 3.4 & 41 & 2.8 & 0.833 \\
\hline \hline
\end{tabular}

Through all periods, there was non- statistically significant difference between mean maximum mouth openings in the two groups

\section{Statistical analysis of Protrusive movement in both groups during postoperative follow up period}

TABLE (3) The mean differences, standard deviation (SD) values and results of paired t-test for the changes by time in protrusive movement of each group

\begin{tabular}{|c|c|c|c|c|}
\hline 官 & Period & $\begin{array}{c}\text { Mean } \\
\text { difference }\end{array}$ & SD & P-value \\
\hline \multirow{6}{*}{ 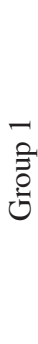 } & 3 months -6 months & 0.5 & 0.8 & 0.096 \\
\hline & 6 months -9 months & 0.2 & 1.7 & 0.716 \\
\hline & 9 months -12 months & 0.1 & 0.9 & 0.726 \\
\hline & 3 months -9 months & 0.7 & 1.3 & 0.132 \\
\hline & 3 months -12 months & 0.8 & 1 & $0.037 *$ \\
\hline & 6 months -12 months & 0.3 & 1.3 & 0.496 \\
\hline \multirow{6}{*}{ 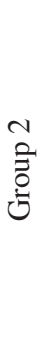 } & 3 months -6 months & 0.1 & 0.9 & 0.726 \\
\hline & 6 months -9 months & 0.1 & 1.1 & 0.780 \\
\hline & 9 months -12 months & 0.4 & 0.5 & $0.037 *$ \\
\hline & 3 months -9 months & 0.2 & 1.1 & 0.591 \\
\hline & 3 months -12 months & 0.6 & 1.2 & 0.140 \\
\hline & 6 months -12 months & 0.5 & 1.1 & 0.177 \\
\hline
\end{tabular}

*: Significant at $P \leq 0.05$ 
In Group 1, there was non-statistically significant change in mean protrusive movement through all periods except through the period (3 months 12 months) where there was a statistically significant increase in mean protrusive movement.

In Group 2, there was non-statistically significant decrease in mean protrusive movement through all periods except through the period (9 months 12 months) where there was a statistically significant increase in mean protrusive movement.

TABLE (4) The means, standard deviation (SD) values and results of Student's t-test for the comparison between protrusive movement in the two groups

\begin{tabular}{|c|c|c|c|c|c|}
\hline \multirow{2}{*}{$\begin{array}{c}\text { Group } \\
\text { Period }\end{array}$} & \multicolumn{2}{|c|}{ Group 1 } & \multicolumn{2}{c|}{ Group 2 } & \multirow{2}{*}{ P-value } \\
\cline { 2 - 5 } & Mean & SD & Mean & SD & \\
\hline 3 months & 2.6 & 1 & 3.2 & 0.8 & 0.172 \\
\hline 6 months & 3.1 & 1.4 & 3.3 & 0.7 & 0.697 \\
\hline 9 months & 3.3 & 1 & 3.4 & 0.8 & 0.818 \\
\hline 12 months & 3.4 & 1.3 & 3.8 & 0.8 & 0.407 \\
\hline
\end{tabular}

Through all periods, there was non- statistically significant difference between mean protrusive movements in the two groups.

\section{Statistical analysis of ipsilateral excursion in both groups during postoperative follow up period}

TABLE (5) The mean differences, standard deviation (SD) values and results of paired t-test for the changes by time in ipsilateral excursion of each group

\begin{tabular}{|c|c|c|c|c|}
\hline 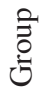 & Period & $\begin{array}{c}\text { Mean } \\
\text { difference }\end{array}$ & SD & P-value \\
\hline \multirow{6}{*}{ 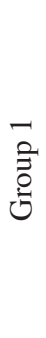 } & 3 months -6 months & 0.3 & 0.5 & 0.081 \\
\hline & 6 months -9 months & -0.4 & 0.7 & 0.104 \\
\hline & 9 months -12 months & 0.4 & 0.7 & 0.104 \\
\hline & 3 months -9 months & -0.1 & 1 & 0.758 \\
\hline & 3 months -12 months & 0.3 & 1.1 & 0.434 \\
\hline & 6 months -12 months & 0 & 0.8 & 1.000 \\
\hline
\end{tabular}

\begin{tabular}{|c|c|c|c|c|}
\hline & 3 months -6 months & 0.3 & 0.8 & 0.279 \\
\cline { 2 - 5 } & 6 months -9 months & -0.2 & 1 & 0.555 \\
\cline { 2 - 5 } 苛 & 9 months -12 months & 0.3 & 0.9 & 0.343 \\
\cline { 2 - 5 } & 3 months -9 months & 0.1 & 1.2 & 0.798 \\
\cline { 2 - 5 } & 3 months -12 months & 0.4 & 1 & 0.223 \\
\cline { 2 - 5 } & 6 months -12 months & 0.1 & 1.1 & 0.780 \\
\hline
\end{tabular}

In Group 1, there was non-statistically significant change in mean ipsilateral excursion through all periods.

In Group 2, there was non-statistically significant change in mean ipsilateral excursion through all periods.

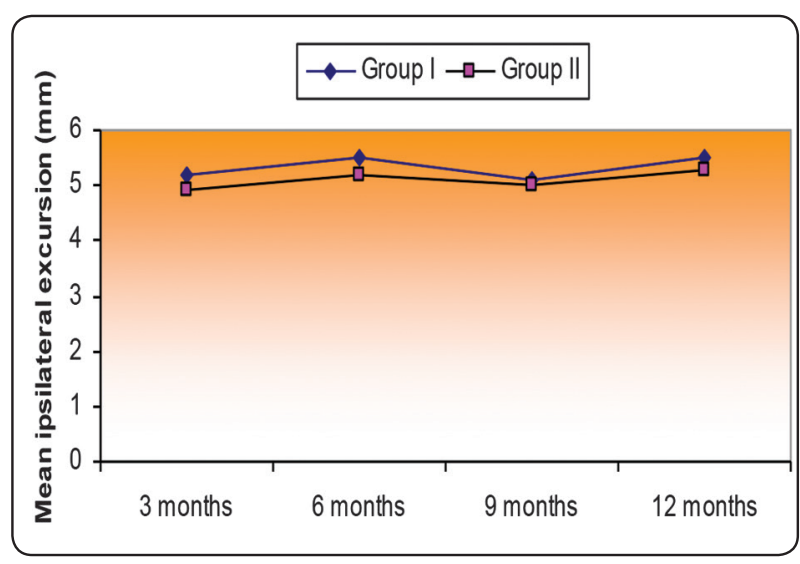

Fig. (6) Mean values of ipsilateral excursion of both groups

TABLE (6) The means, standard deviation (SD) values and results of Student's t-test for the comparison between ipsilateral excursions in the two groups

\begin{tabular}{|l|c|c|c|c|c|}
\hline \multirow{2}{*}{ Group } & \multicolumn{2}{|c|}{ Group 1 } & \multicolumn{2}{c|}{ Group 2 } & \multirow{2}{*}{ P-value } \\
\cline { 2 - 5 } Period & Mean & SD & Mean & SD & \\
\hline 3 months & 5.2 & 0.8 & 4.9 & 1.3 & 0.538 \\
\hline 6 months & 5.5 & 0.5 & 5.2 & 1.2 & 0.487 \\
\hline 9 months & 5.1 & 0.7 & 5 & 0.7 & 0.754 \\
\hline 12 months & 5.5 & 0.5 & 5.3 & 0.8 & 0.526 \\
\hline
\end{tabular}

Through all periods, there was no statistically significant difference between mean ipsilateral excursions in the two groups. 
IV. Statistical analysis of Contra-lateral excursion in both groups during postoperative follow up period

TABLE (7) The mean differences, standard deviation (SD) values and results of paired t-test for the changes by time in contra-lateral excursion of each group

\begin{tabular}{|c|c|c|c|c|}
\hline $\begin{array}{l}\text { ?े } \\
\text { రై }\end{array}$ & Period & $\begin{array}{c}\text { Mean } \\
\text { difference }\end{array}$ & SD & P-value \\
\hline \multirow{6}{*}{$\begin{array}{l}\vec{\Xi} \\
\stackrel{0}{0}\end{array}$} & 3 months -6 months & 0.2 & 0.6 & 0.343 \\
\hline & 6 months -9 months & 0.4 & 2.4 & 0.613 \\
\hline & 9 months -12 months & 0.2 & 1 & 0.555 \\
\hline & 3 months -9 months & 0.6 & 2.5 & 0.460 \\
\hline & 3 months -12 months & 0.8 & 1.9 & 0.223 \\
\hline & 6 months -12 months & 0.6 & 1.9 & 0.343 \\
\hline \multirow{6}{*}{$\begin{array}{l}\text { N } \\
\stackrel{\Xi}{0} \\
\stackrel{0}{0}\end{array}$} & 3 months -6 months & -0.1 & 1.1 & 0.780 \\
\hline & 6 months -9 months & 0.5 & 2.1 & 0.464 \\
\hline & 9 months -12 months & 0.3 & 0.7 & 0.193 \\
\hline & 3 months -9 months & 0.4 & 2.3 & 0.591 \\
\hline & 3 months -12 months & 0.7 & 2.5 & 0.406 \\
\hline & 6 months -12 months & 0.8 & 2.3 & 0.309 \\
\hline
\end{tabular}

In Group 1, there was non-statistically significant decrease in mean contra-lateral excursion through all periods.

In Group 2, there was non-statistically significant decrease in mean contra-lateral excursion through all periods.
TABLE (8) The means, standard deviation (SD) values and results of Student's t-test for the comparison between contra-lateral excursion in the two groups

\begin{tabular}{|c|c|c|c|c|c|}
\hline \multirow{2}{*}{$\begin{array}{r}\text { Group } \\
\text { Period }\end{array}$} & \multicolumn{2}{|c|}{ Group 1 } & \multicolumn{2}{c|}{ Group 2 } & \multirow{2}{*}{ P-value } \\
\cline { 2 - 5 } & Mean & SD & Mean & SD & \\
\hline 3 months & 3.7 & 1 & 3.9 & 1 & 0.669 \\
\hline 6 months & 3.9 & 1.3 & 3.8 & 0.8 & 0.836 \\
\hline 9 months & 4.3 & 1.8 & 4.3 & 1.6 & 1.000 \\
\hline 12 months & 4.5 & 1.2 & 4.6 & 1.9 & 0.889 \\
\hline
\end{tabular}

Through all periods, there was non-statistically significant difference between mean contra-lateral excursions in the two groups.

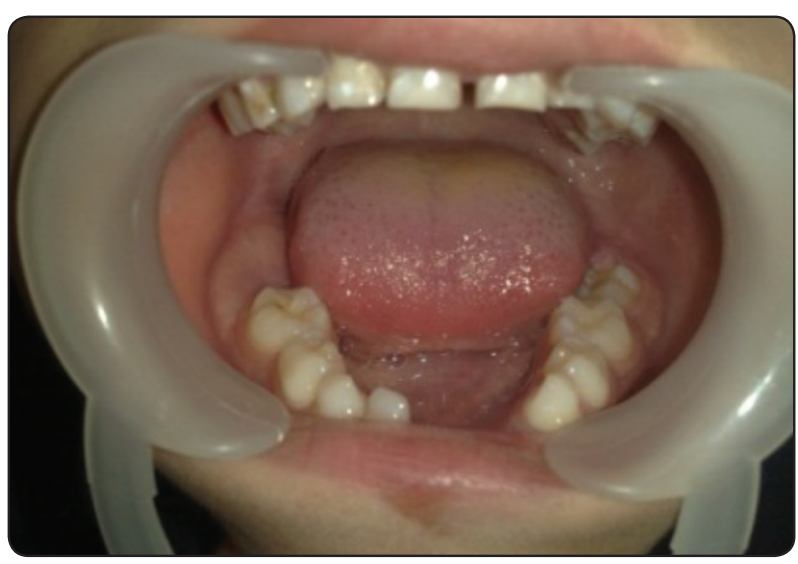

Fig. (7) 12 month postoperative view of case of group two showing acceptable maximum mouth opening

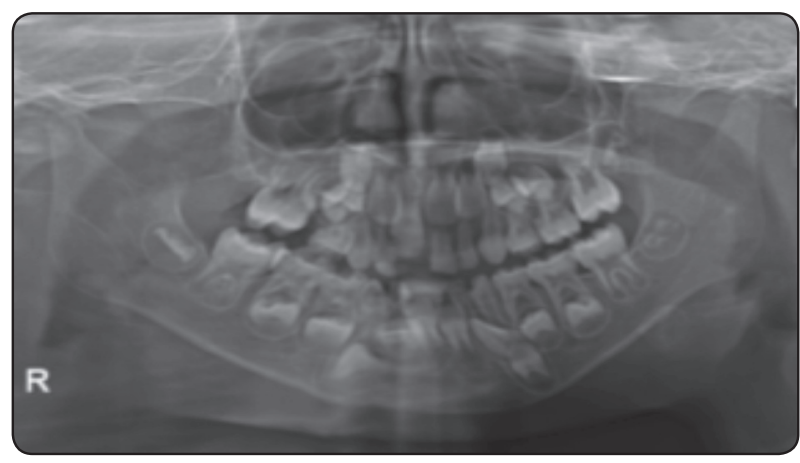

Fig. (8) 12 month post-operative panoramic view showed normal boundaries of joint space in patients of group one 


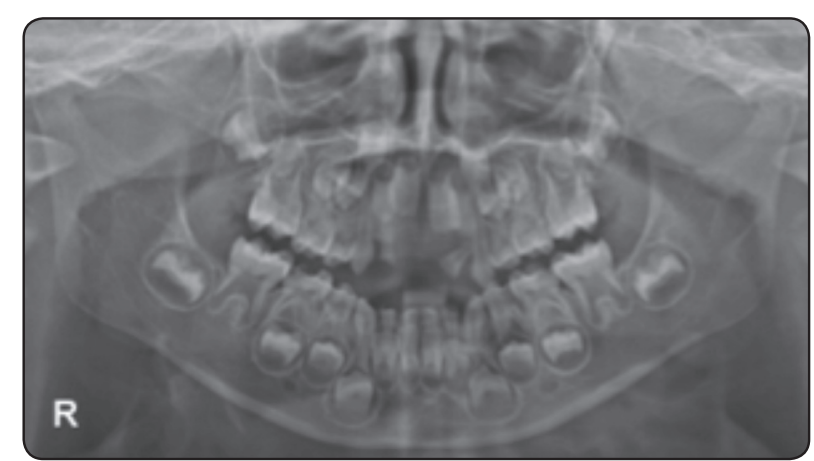

Fig. (9) 12 month post-operative panoramic view showed normal boundaries of joint space in patients of group two

\section{DISCUSSION}

The management of the fractures in the pediatric patient requires an understanding of craniofacial growth, anatomical differences of the pediatric craniofacial skeleton, and the special needs of the child and family. Understanding these differences is the first step in formulating a specially tailored treatment plan that achieves good function and form without causing undue growth restriction or debilitation. Unlike the adult, the child must not only recover from the effects of the traumatic event, but also must continue the normal process of growth and development. For the oral and maxillofacial surgeon, the familiarity with these injuries will allow for rapid and accurate assessment, timely treatment and favorable results. ${ }^{2}$

The incidence of facial fractures is lower in the pediatric population than in the adult population and represents $1-14.7 \%$ of the facial fractures in the general population. ${ }^{3}$ The reasons cited for this low incidence include, small volume of facial mass relative to the calvarium, the relative resilience of the pediatric skeleton and the protected environment in which children live, leading to less exposure to typical mechanism of injury. ${ }^{2-4}$ The degree of precision required in a children is not quite as great as in an adult, as the adaptive potential of the alveolar bone and the replacement of deciduous teeth by permanent teeth can bring about various degrees of self-correction. The high osteogenic potential of the pediatric mandible is responsible for a low complication rate. ${ }^{5}$ The specific treatment of mandibular fractures depends on location of the fracture, degree of bony displacement, occlusal status, and dentition status of the child.

The age of group two in this current study (610 years) characterized by instability of dentition as deciduous teeth either loose, lost, or badly decayed, while permanent dentition is still erupting with uncompleted roots formation. This is the foremost indication of for closed reduction and indirect fixation by labiolingual splint to avoid injuries of the teeth germ of permanent teeth.

The acrylic labiolingual splint is the most famous means of indirect fixation of pediatric mandibular body fractures. The superior edges of the splint flanges were placed cervical to the free gingival margin at least $1 \mathrm{~mm}$. The labial and lingual plates of the splint were connected by soft stainless steel wire loop posteriorly, which allowed ease of manipulation, adaptation, and fine adjustment of the splint. The inferior edges of the splint flanges were harbored the end cuts circummandibular wires to prevent traumatization of the lip and the cheek during the fixation period. It could be fixed by $2-4$ circummandibular wiring.

The relatively bulky size of the acrylic labiolingual splint which fitted to fairly small size pediatric mandibular patients directed the author to study the effect of splint on mandibular function movement during the fixation period(30days) and otherwise deleterious effect on TMJ development. This suggestion is supported by Karlo et al ${ }^{13}$ study, they concluded that; the mandibular condyle is subject to significant changes in size and shape during childhood. Although there is a lack of literature up to our knowledge denoting the indirect impact of acrylic labiolingual splints on TMJ .

The patients in the current study were divided into two equal groups based on patient's ages to evaluate the effect of acrylic splint on mandibular 
function movement in preschool children (group one) which might refuse feeding. Swallowing or even open and closed their mouth. Also the small sized jaw of preschool age patients may be the additional limitation factors.

The American Academy of Pediatric Dentistry (AAPD) recognizes that disorders of the temporomandibular joint (TMJ), masticatory muscles, and associated structures occasionally occur in infants, children, and adolescents. This guideline is intended to assist the practitioner in the recognition and diagnosis of temporomandibular disorders (TMD) and to identify possible treatment options. ${ }^{14}$

Plenty of research considered the direct effect of different treatment modalities for reduction and fixation for treatment of condylar and subcondylar fractures on TMJ dysfunction rather than the indirect impact of acrylic labiolingual splint which could limited the normal mandibular movement and hazardous feedback effect on TMJ. ${ }^{15-20}$

As regard to evaluation the late consequence on TMJ functions during the fixation period (30 days); statistically; Through all one year postoperative follow periods, there were non statistically significant differences between mean maximum mouth openings, mean ipsilateral excursions and mean contra-lateral excursions between the two groups and in each group. Consequently, labiolingual splint definitely had neither directly effect on TMJ function in cases of mandibular body fractures nor indirectly harmful effect on TMJ .

Khider et $\mathrm{al}^{21}$ study concluded that, the acrylic labiolingual splint is recommended in management of pediatric mandibular fractures due to the following advantages: It is a noninvasive method of reduction and fixation, It is obviate the need of open reduction and the possibility of harming the developing dentition, It is allows treatment in an outpatient setting without the need for general anesthetic or hospital admission and the total outcome charge is less than the other fixation systems. Although the previous conclusions not were the primary scope of the current study but all these findings were also noticed during the evaluation and through one year postoperative follow up of the our two groups. In addition to these previous advantages, the current study revealed that, the acrylic labiolingual splints had no deleterious effect on TMJ function.

So the current study recommended that ;closed reduction and indirect fixation with acrylic labiolingual splint is the safest mean of treatment of pediatric mandibular fractures including all regions of dental bearing area.

\section{CONCLUSION}

From results of the current study it was noted that closed reduction and indirect fixation with acrylic labiolingual splint is the safest mean of treatment of pediatric mandibular fractures including all regions of dental bearing area without deleterious effect on TMJ functional activities.

\section{REFERENCES}

1- Anderson PJ. Fractures of the facial skeleton in children. Injury 1995;26:47-50

2- Kaban LB, Mulliken JB, and Murray JE: Facial fractures in children: An analysis of 122 fractures in 109 patients. Plast Recon Surg 59: 151, 1977

3. Okeson JP. Temporomandibular joint pains. In Bell's Oral and Facial Pain, 7th edition. Chicago, IL; Quintes-sence Publishing; 2014:327-69.

4. Greco CM, Rudy TE, Turk DC, Herlich A, Zaki HH. Traumatic onset of temporomandibular disorders: Positive effects of a standardized conservative treatment program. Clin J Pain 1997;13(4):337-47.

5. Fischer DJ, Mueller BA, Critchlow CW, LeResche L. The association of temporomandibular disorder pain with history of head and neck injury in adolescents. J Orofac Pain 2006;20(3):191-8.

6. Imahara SD, Hopper RA, Wang J, Rivara FP, Klein MB. Patterns and outcomes of pediatric facial fractures in the United States: A survey of the National Trauma Data Bank. J Am Coll Surg 2008;207(5):710-6. 
7. Akhter R, Hassan NM, Ohkubo R, et al. The relationship between jaw injury, third molar removal, and orthodontic treatment and TMD symptoms in university students in Japan. J Orofac Pain 2008;22(1):50-6.

8. Leuin SC, Frydendall E, Gao D, Chan KH. Temporomandibular joint dysfunction after mandibular fracture in children: A 10 year review. Arch Otolarygol Head Neck Surg 2011;137(1):10-14.

9- Dror Aizenbud, Hagai Hazan-Molina, Omri Emodi Adi Rachmiel. The management of mandibular body fractures in young children Dental Traumatol 2009; 25: 565-570

10. Ailing HI: Mandibular fractures. In Ailing III CC and Osborn DB (Ed): Maxillofacial trauma. Lea and Febiger, Philadelphia, USA pp238, 1988

11. Faust RA, Younes AA, Gottlieb W, Phillips CD. Maxillary fractures in children. WebMD Web site. Available from: http://www.emedicine.com/ent/topic491.htm.

12. Ferreira PC, Amarante JM, Silva PN, Rodrigues JM, Choupina MP, Silva AC, et al. Retrospective study of 1251 maxillofacial fractures in children and adolescents. Plast Reconstr Surg 2005;115:1500-8.

13- Karlo, C A; Stolzmann, P; Habernig, S; Müller, L; Saurenmann, T; Kellenberger, C J Size, shape and agerelated changes of the mandibular condyle during hildhood. European Radiology, 20(10):2512-17. 2010.

14- American Academy of Pediatric Dentistry Guideline on Acquired Temporomandibular Disorders in Infants,
Children, and Adolescents .reference manual 3 7(15): 272- 78, 2015

15. Shelby C. Leuin, MD; Emily Frydendall, BA; Dexiang Gao. Temporomandibular Joint Dysfunction After Mandibular Fracture in ChildrenARCH Otolaryngol Head Neck Surg/ Vol 137 (No. 1), Jan 2011

16. Helkimo M. Studies on function and dysfunction of the masticatory system, I: an epidemiological investigation of symptoms of dysfunction in Lapps in the north of Finland. Proc Finn Dent Soc. 1974;70(2):37-49.

17. Helkimo M. Studies on function and dysfunction of the masticatory system, II: index for anamnestic and clinical dysfunction and occlusal state. Sven Tandlak Tidskr. 1974;67(2):101-121.

18. Thorén H, Hallikainen D, Iizuka T, Lindqvist C. Condylar process fractures in children: a follow-up study of fractures with total dislocation of the condyle from the glenoid fossa. J Oral Maxillofac Surg. 2001;59(7):768-774.

19. Choi J, Oh N, Kim IK. A follow-up study of condyle fracture in children. Int J Oral Maxillofac Surg. 2005; 34(8):851-858.

20. Deleyiannis FW, Vecchione L, Martin B, Jiang S, Sotereanos G. Open reduction and internal fixation of dislocated condylar fractures in children: long-term clinical and radiologic outcomes. Ann Plast Surg. 2006; 57(5):495-501.

21- Khider et al. Conservative treatment versus bioabsorbable plating system in the management of pediatric mandibular fractures EDJ volum58 3499-3507, 2012 